\title{
FACTORS FOR LIMITED APPLICATION OF IDENTICAL PROTOCOLS IN INTENSIVE CARE UNITS
}

\author{
V. Lalova ${ }^{1 *}$, G. Petrova ${ }^{1}$, H. Kulina ${ }^{2}$, E. Merdjanova ${ }^{1}$ \\ ${ }^{1}$ Department of "Nursing", Faculty of Public Health, Medical University of Plovdiv, Plovdiv, Bulgaria \\ ${ }^{2}$ Department of Applied Mathematics and Modeling, Faculty of Mathematics and Informatics, \\ University of Plovdiv "Paisii Hilendarski”, Plovdiv, Bulgaria
}

\begin{abstract}
Introduction: Intensive units have been provided cares at different levels of support for intensive patients. The development of protocols for the work of nurses aims to facilitate their day-to-day activities, improving the outcomes and safety of patients and all staff. Following this concept, the role of intensive cares has been rapidly expanded over the last 20 years (3). The performance of nurses, as an integral part of multidisciplinary teams at the ICUs is evidence, that mortality and morbidity can be prevented, thanks to the usage of protocols for every - day obligations.

Materials and methods: The main aim of this study is to analyze and differentiate the main reasons for the limited use of protocols in intensive care units. It is important to assess the activities, carried out by the nurses, who do not have experience working in ICUs. Has been used a survey method, data have been analyzed by using the software package SPSS v. 21.0 and graphics have been prepared by using the program Microsoft Excel' 97.

Results: According to the medical specialist from the 5th ICUs in university hospitals, the most common reasons are lack of time to implement, lack of finance and lack of medical specialists.

Discussion: We should have developed the more flexible frameworks, which have been accepted by standards of cares, which will improve the quality of cares. There are concerns, that the lack of nurses in intensive units has been increased.
\end{abstract}

Key words: protocols, ICUs, nursing cares;

\section{INTRODUCTION}

Intensive care units are ready to occupy an increasingly important and significant place, as part of the world's health establishments $(1,2)$. The development and implementation of protocols about the work of nurses, aims to facilitate their day-to-day activities, improving the outcomes and safety of patients and all staff. Following this concept, the role of intensive care has been rapidly expanded over the last 20 years (3). The future of patients` care will be underpinned by new technology developments, as well as the usage of the established frameworks and rules for the activities of medical specialists, working there. With this difficult process of development, must be ensured that the objectives of intensive cares will be effectively implemented in future $(4,5)$.

\footnotetext{
*Correspondence to: V. Lalova, Department of

"Nursing", Faculty of Public Health, Medical

University of Plovdiv, Bulgaria, Bul. "Vasil

Aprilov" 15A, Plovdiv - 4002

suzy_lalova@yahoo.com
}

\begin{abstract}
AIM
The main aim of this study is to analyze and differentiate the main reasons for the limited use of protocols in intensive care units. It is important to assess the activities, carried out by the nurses, who are working in ICUs. We wanted to study their effectiveness and all the benefits for the organization of working process.
\end{abstract}

\section{MATERIALS AND METHODS}

Has been used a survey method, data have been analyzed by using the software package SPSS v. 21.0 and graphics have been prepared by using the program Microsoft Excel '97.

\section{RESULTS}

To the question "What do you think are the reasons for limited application of protocols the intensive care units?", the respondents respond on a scale from 1 to 5 with "no", "not really", "can`t judge" , "closer to yes" and "yes" for the following reasons: 
LALOVA V., et al.

$>$ limited resources for the professional development of medical staff;

$>$ lack of support from doctors;

$>$ unwillingness of doctors to work with protocols;

$>$ unwillingness of nurses to work with protocols;

$>$ difficulties in training with them;

The opinion of the doctors and nurses, whether the limited resources for their professional development are the reason for the limited usage of protocols, has been shown in Figure 1 - The Kruskal-Wallis H test with significance $\mathrm{p}=0.01$ indicates, that there is a statistically significant relationship between the medical establishment and the view, that the lack of professional development of the nurses is an important reason for the limited usage of protocols. It can be seen from Figure 1, that the respondents with a positive response from the "Kaspela" hospital are predominantly prevalent. At the same time, with the MannWhitney $U$ test $(p=0.05)$, there is no statistically significant difference between the opinion of the doctors on one hand and the opinion of the nurses on the other.

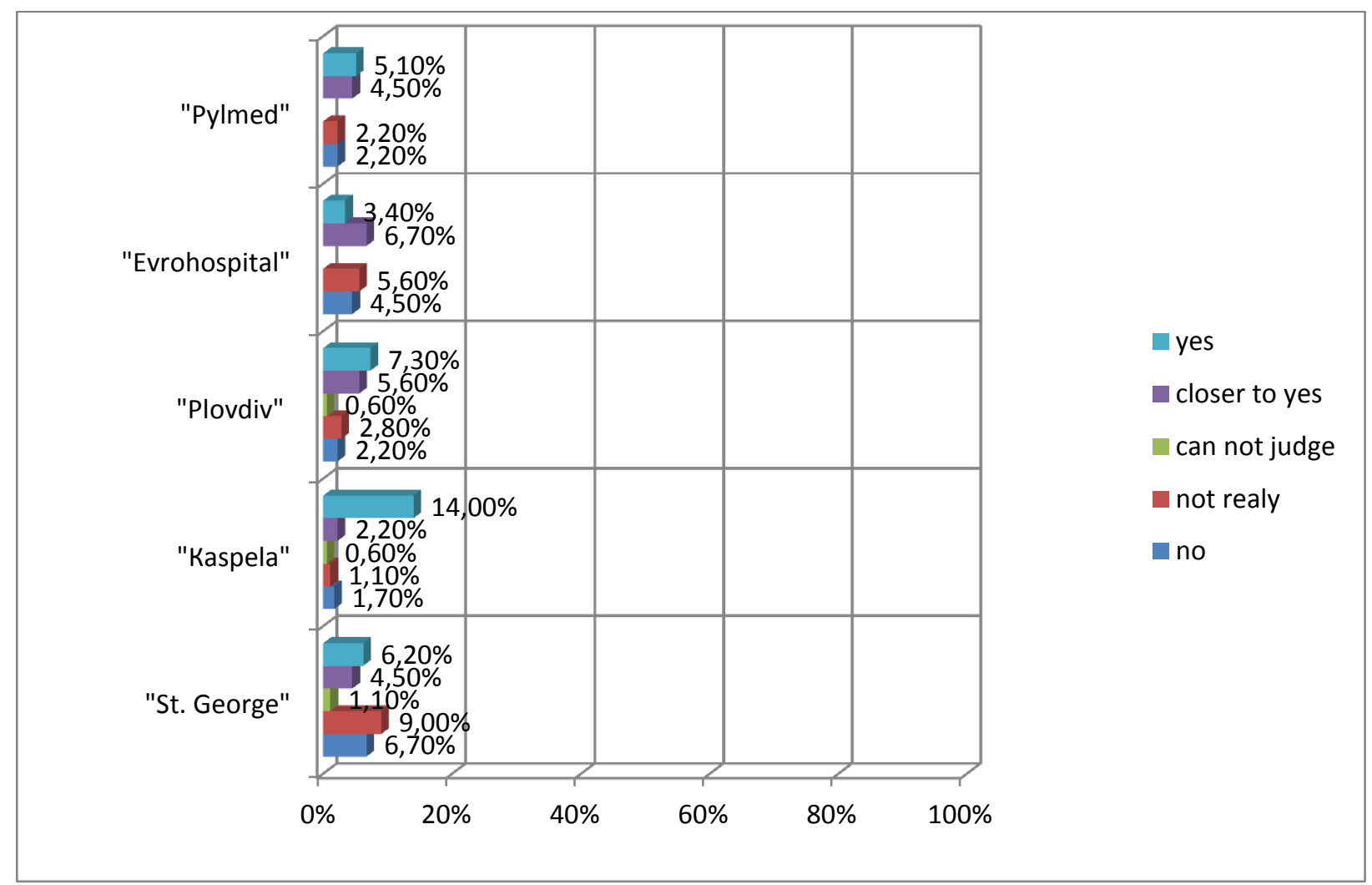

Figure 1. Limited opportunities for professional development of nurses in intensive care unit.

Respondents from the University Hospital "St.George", believe that the professional development of each employee depends on his / her desire, motivation, skills and could not be the reason for their unwillingness to work with protocols $(\mathrm{n}=12 \pm 6.7 \%) \mathrm{p}=0.001\left(\chi^{2}=39,727^{\mathrm{a}}\right.$ $\mathrm{df}=16)$. The other respondents believe, that the professional development of nurses is limited to some management functions, which explains the lack of motivation for more efficient work through the usage of protocols.

When it comes to lack of support from doctors Figure 2, with a level of significance $p=0.01$, we can re-think, that the opinion in different statistically. For instance, in "Kaspela" hospital, the number of respondents with "no" and "yes" is the same. On this issue, however, the opinion of doctors and nurses differs statistically - Figure 3. The difference comes from the categorical prevalence of "no" answers from doctors, while nurses answer the question with "rather not", meaning that doctors are those, who have influence on the introduction of protocols in the intensive units $\left(\chi^{2}=53,236^{\mathrm{a}} \mathrm{df}=16\right)$. The medical specialists from the units form effective and high-quality teams, and the unified work and support in carrying out the activities is part of their daily work process. 


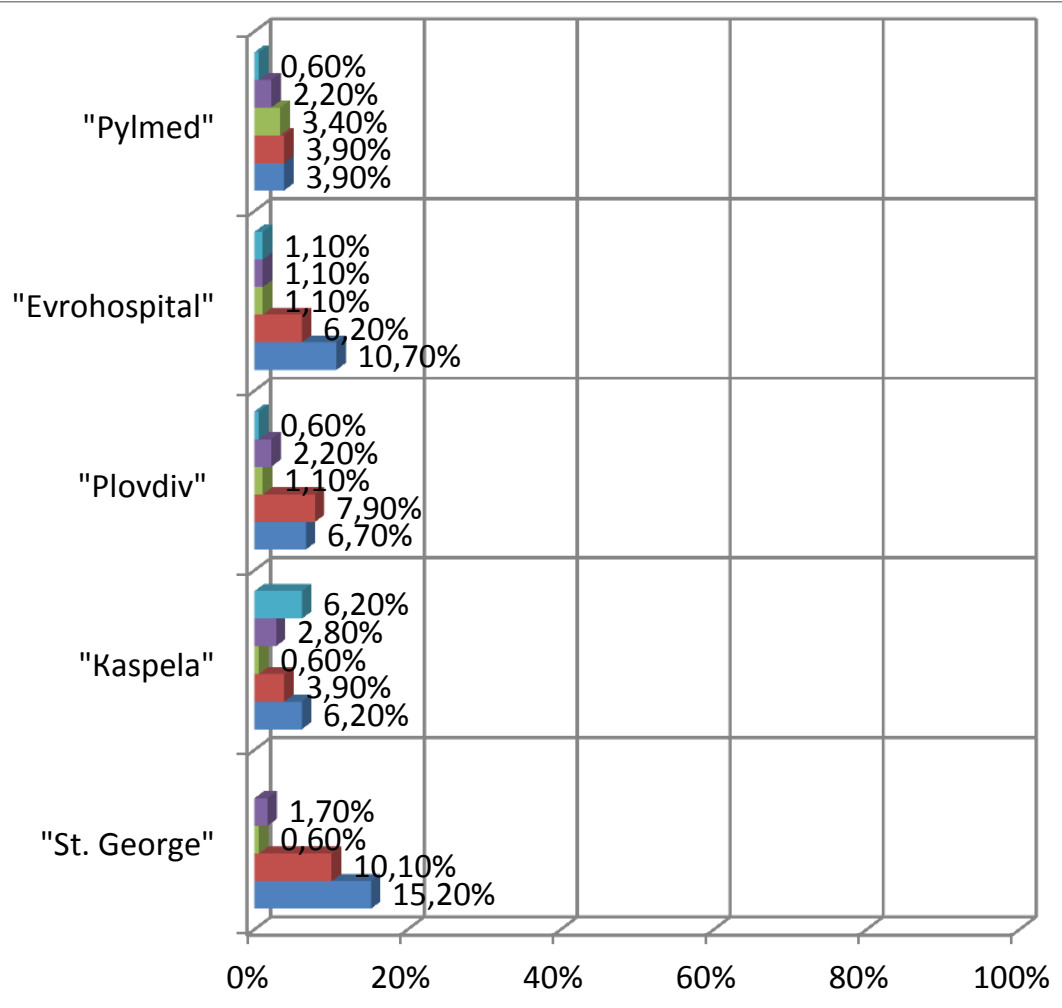

yes

closer to yes

can not judge

not realy

no

Figure 2. Lack of support from doctors in intensive care units.

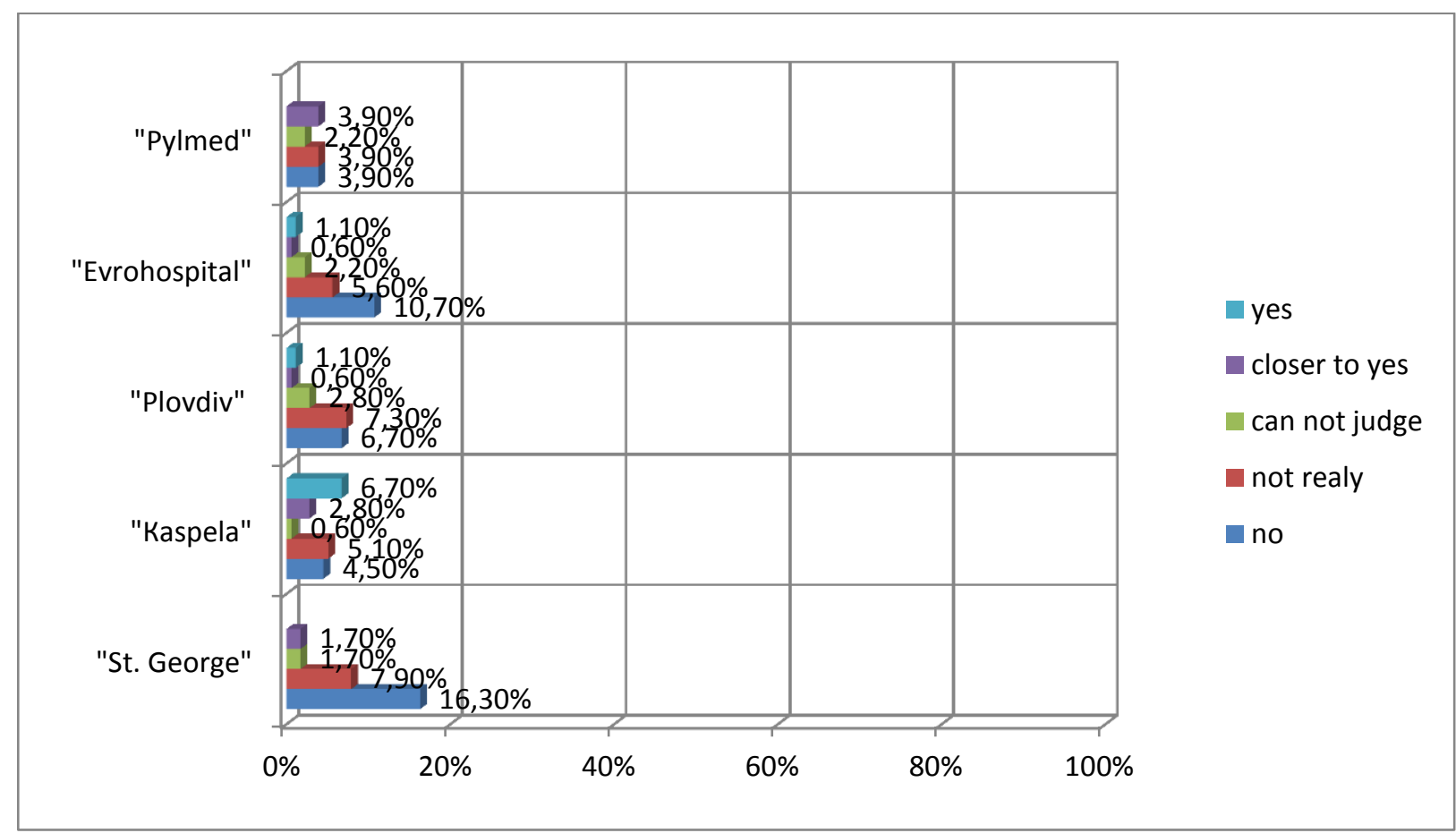

Figure 3. Unwillingness of doctors to work with protocols.

Doctors from the research institutes have years of experience and have developed frameworks and rules for working with clinical protocols covering a wide range of medical activities. There is a narrower range of manipulations in the nursing activities, which are subject to be protocolized. Negative is the opinion of the respondents regarding to unwillingness of doctors to work with protocols $\mathrm{p}=0.001$ $\left(\chi^{2}=60,597^{\mathrm{a}} \mathrm{df}=16\right)$.
The unwillingness of nurses to work with protocols, as a reason for their limited usage is presented in Figure 4, where $\mathrm{p}=0.001$ $\left(\chi^{2}=97,130^{\mathrm{a}} \mathrm{df}=16\right)$. A strong difference is observed with "Evrohospital" respondents, who believe that nurses are unwilling to work with clinical protocols. 


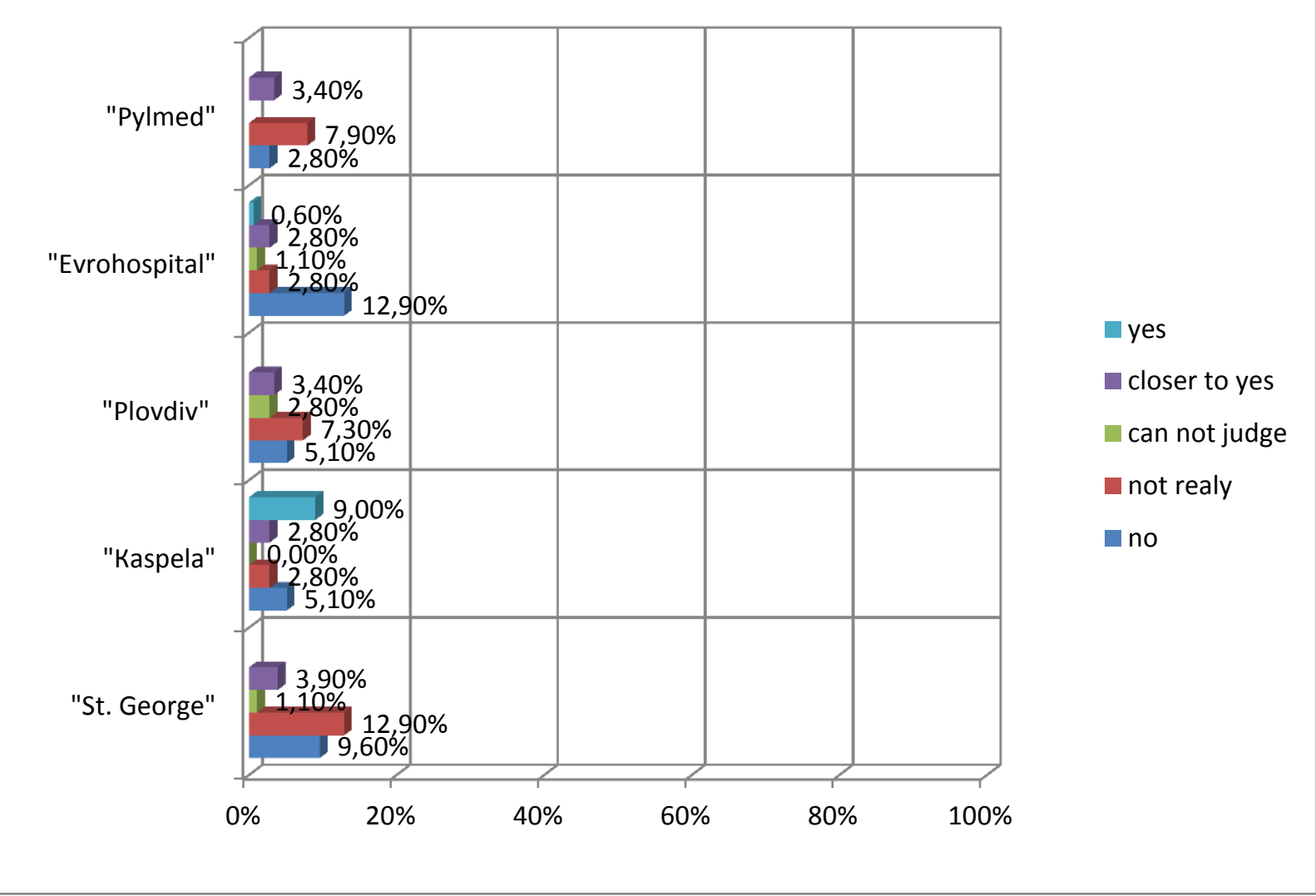

Figure 4. Unwillingness of nurses to work with protocols;

Regarding to difficulties related to the training on protocols, the respondents from all the studied units are categorical, that there are no or rather missing problems in training $\left(\chi^{2}=19,271^{\mathrm{a}} \mathrm{df}=16\right)$. The activities described in the protocols are clearly justified, and each step and stage of the manipulation is clearly exposed to the specifics of the intensive work (Figure 5).
In conclusion, we can say that overcoming perceived barriers of using equal protocols within ICUs, requires constantly evolving medical staff to support the physician. According to the specialists, working in ICUs, one of the main reasons for the limited use of protocols for work in intensive care units is the limited professional development of the nurses. The nurses have a desire to use protocols in their daily work without having any difficulties working with them.

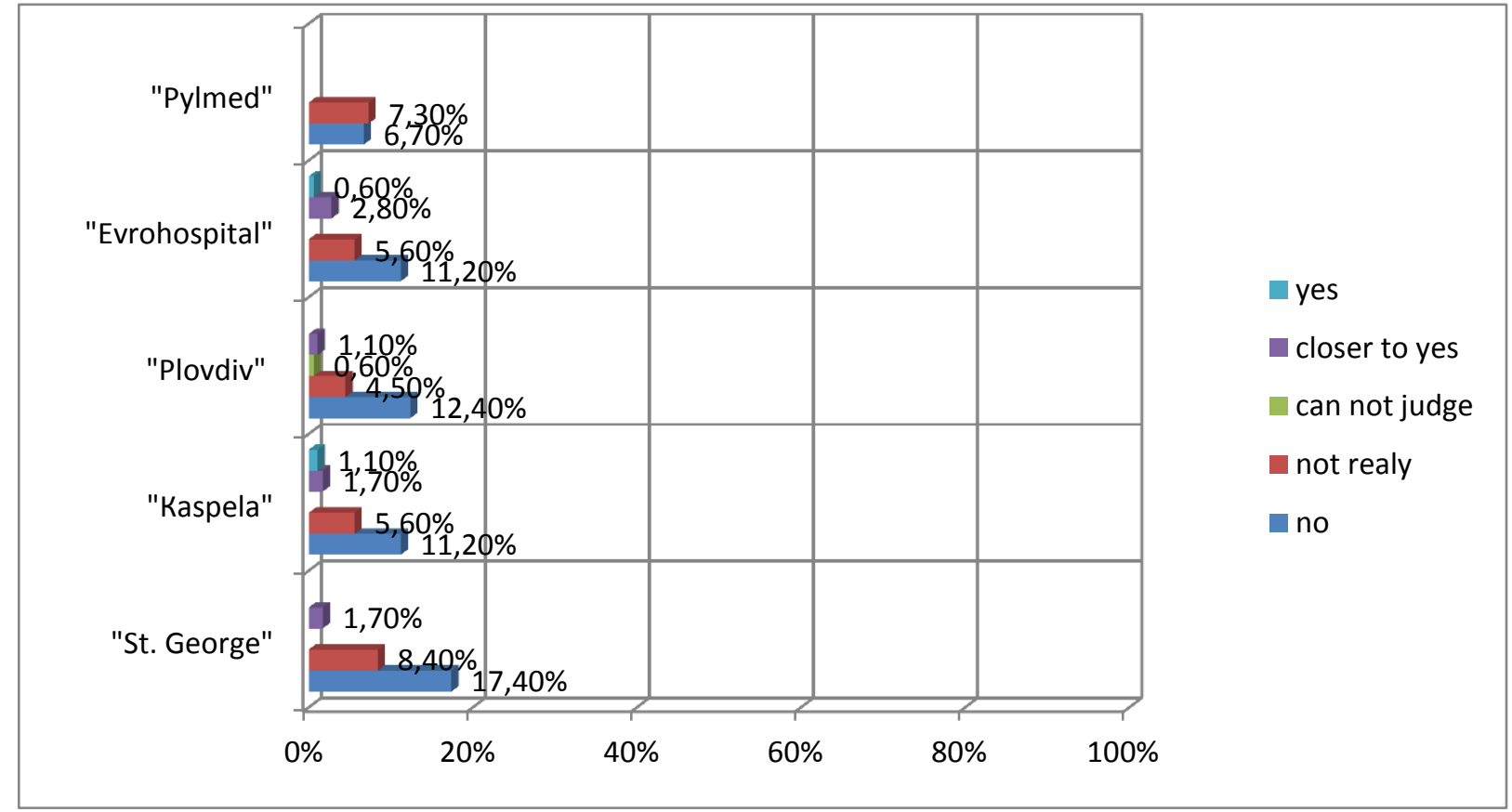

Figure 5. Difficulties related to protocol training. 


\section{REFERENCES}

1. Spreen AE, Schuurmans MJ: Visiting policies in the adult intensive care units: a complete survey of Dutch ICUs. Intensive Crit Care Nurs, 27:27-30, 2011.

2. Talmor D, Shapiro N, Greenberg D, et al. When is critical care medicine costeffective? A systematic review of the costeffectiveness literature. Crit Care Med.;34:2738-2747, 2006.

3. Tanios MA, de Wit M, Epstein SK, et al. Perceived barriers to the use of sedation protocols and daily sedation interruption: a multidisciplinary survey. $J$ Crit Care; 24:66-73, 2009.
LALOVA V., et al.

4. The Acute Respiratory Distress Syndrome Network. Ventilation with lower tidal volumes as compared with traditional tidal volumes for acute lung injury and the acute respiratory distress syndrome. $N$ Engl $J$ Med; 342:1301-8, 2000.

5. Thompson DR, Hamilton DK, Cadenhead CD, Swoboda SM, Schwindel SM, Anderson DC, Schmitz EV, St Andre AC, Axon DC, Harrell JW, Harvey MA, Howard A, Kaufman DC, Petersen C: Guidelines for intensive care unit design. Crit Care Med, 40:1586-1600, 2012. 